\title{
Redes multicódigos: possibilidades semióticas para o ativismo global
}

Francisco José Paoliello Pimenta Universidade Federal de Juiz de Fora/UFJF 


\section{Resumo}

Apresentação de pesquisa sobre possíveis relações entre a utilização de suportes hipermídia, como instrumentos de estímulo a ações políticas diretas de âmbito global, e a formação de hábitos de conduta ligados à democracia participativa e a um internacionalismo renovado. A investigação envolve a análise de sites voltados para a organização e divulgação de eventos e manifestações de caráter global, com ênfase nos processos semióticos multicódigos. Ao final, são lançadà propostas de ação com base na noção de signo genuíno do lógicó_Chârlès Sanders Pèirce.

\section{Palavras-chave}

hipermídia, ativismo político, semiótica

\section{Abstract}

Research concerning possible relationships between hypermedia, as a tool for global direct political actions, and the formation of conduct habits connected to participatory democracy and a renewed internationalism. This involves an analysis about global demonstrations and events organization and releasing, stressing multicode semiotic processes. In the end, action proposals based on the logician Charles Sanders Peirce's notion of genuine sign are launched.

\section{Key words}

hypermedia, political activism, semiotic 


\section{Introdução}

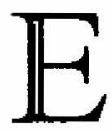

sta comunicação trata de questões contidas em projeto de pesquisa de pós-doutorado intitulado Possibilidades da Hipermídia no Ativismo Global, voltado para a investigação sobre possíveis relações entre a utilização de suportes hipermídia, como instrumentos de estímulo a ações políticas diretas de âmbito global, e a formação de hábitos de conduta ligados à democracia participativa e a um internacionalismo renovado.

A partir deste campo mais amplo, nos deteremos aqui em aspectos relacionados à segunda hipótese do experimento, segundo a qual, "organizações voltadas para o estímulo à participação politica direta de âmbito global ainda não têm utilizado os recursos hipermídia como uma de suas formas de mobilização; em toda a sua efetividade". Estará em foco, especialmente, a utilização de suportes hipermídia na mobilização de protesto à reunião dos dirigentes dos paises mais industrializados do mundo, o G8, ocorrida em Evian, entre os meses de maio e junho de 2003.

Conforme já detalhado em outros trabalhos, desenvolvidos nos últimos dez anos, argumenta-se que os atuais meios técnicos possibilitaram a construção de processos sígnicos cada vez mais sofisticados, pela articulação dos códigos verbal, visual, sonoro e, até mesmo, gestual, este último estimulado pela interatividade. Tal complexo multicódigos supera a arbitrariedade do verbal, hegemônico até agora, e abre espaço para signos crescentemente analógicos em relação a seus objetos. Isto porque os códigos não-verbais têm características próprias, o que implica em processos diferenciados já a partir da percepção, na relação com seus referentes e também nos 
efeitos que geram nos intérpretes. (Pimenta, 1993: pp.75-80; 1998: pp.85-109; 1999A: pp.62-9; 1999B: pp.77-90; 1999C: pp.67-77; 2001A: CD; 2001B: CD; 2002: CD; 2003, cd).

\section{Dias de resistência em Evian}

A partir destas premissas, passamos, então, a descrever as observações que pudemos obter relativas à mobilização Evian 2003, decorrentes da análise sobre o grau de utilização efetiva dos recursos hipermídia como forma de mobilização, por parte das organizaçôes voltadas para o estímulo à participação política direta de âmbito global. Estes "Dias de Resistência" duraram praticamente uma semana, desde as primeiras manifestações de "recepção" às delegações ligadas ao encontro do G8, ocorridas na quarta-feira, dia 28 de maio, até o final da cúpula, na terça-feira, dia 3 de junho.

Antes do encontro, previa-se que o dia de ação mais importante seria no domingo, dia $1^{\circ}$. Com o afastamento da maioria das organizações institucionais de esquerda, por causa de pressões políticas, foram planejados como ações principais dois bloqueios organizados pelos anarquistas, durante a manhã, e um protesto de trabalhadores da região de Lausanne, à tarde, com a participação de manifestantes de vários acampamentos. Com o cerco policial a Evian, para evitar o acesso dos ativistas, Lausanne passou a ser a referência para as manifestações. Cercada por montanhas, pelo grande lago Leman e próxima a duas fronteiras, Evian havia sido escolhida para o encontro exatamente por seu isolamento geográfico, já que o acesso à cidade pode ser facilmente fechado.

A região foi dividida em quatro zonas, em ordem decrescente de importância. A Vermelha, onde se localizavam os três hotéis com a maioria dos participantes da cúpula; a Zona 1, que abarcou toda a cidade de Evian, acessível somente a pessoas autorizadas; a Zona 2, com largura de $2 \mathrm{~km}$ e $15 \mathrm{~km}$ de comprimento, onde o centro de mídia oficial ficou situado; e; finalmente, a Zona 3, na área rural, mas, ainda assim, severamente controlada. Foi criada uma "bolha aeronáutica" sobre Evian, e realizado patrulhamento em toda a região, incluindo o lago Leman, em torno do qual se situam as cidades 
de Genebra; Lausanne e Annemasse, entre outras. O ponto fraco da segurança era o número de pessoas envolvidas no encontro oficial, estimado em dez mil, de forma que a maioria ficou numa região de até $30 \mathrm{~km}$ em torno de Evian, principalmente em Lausanne e Genebra. Com isso, embora afastados da cidade, os manifestantes puderam atrapalhar bastante os deslocamentos.

Para isso, foram organizados vários acampamentos, sendo os dois principais montados nas estradas que dão acesso a Evian, o VAAG 4 Tripla Força Anarquista e o Intergalático 4, dos grupos ATTAC, Disobedienti e outros. Pretendeu-se criar um modelo de sociedade não-hierárquica, de forma que os acampamentos já constituíssem, em si, uma ação anti-capitalista, embora tenha havido criticas relativas a uma certa desorganização.

Ocorreram manifestações variadas. Na quinta, dia 29, houve protestos "musicais", próximos a hotéis em Lausanne, e festivos, em Annemasse, com a participação de centenas de manifestantes e moradores, além de demonstrações no túnel de Mont Blanc pela liberdade de movimentos migratórios na Europa. Na sexta, dia 30, houve marcha de cerca de três mil pessoas em Genebra. Vários grupos se deslocaram dos acampamentos, por trem, com a colaboração de ferroviários grevistas, e participaram de manifestações de protesto, em clima predominantemente festivo, próximas a prédios públicos, entre eles o da Organização Mundial do Comércio e da Organização Internacional de Migrações. Neste caso, foram pouco significativos os confrontos diretos com policiais. Houve algumas janelas quebradas e, em resposta, bombas de gás lacrimogêneo.

No sábado, dia 31, manifestantes se concentraram em Lausanne, para aproveitar a oportunidade de protestar diretamente frente aos participantes da Cúpula, que estavam hospedados em Genebra e aguardavam o barco para cruzar o lago em direção a Evian e, se possivel, bloqueá-los. Haviam ocorrido na sexta, e prosseguiram tro sábado, debates em diversas localidades e na Universidade de Genebra sobre estratégias de controle não-privado da educação, da terra e da cultura, além de discussões sobre bloqueios. Muitos ciclistas chegaram durante o dia, vindos de diversas partes da Europa, e todos participaram de três grandes demonstrações à noite. 
A primeira, intitulada O Lago vai Ferver, consistiu de reuniões para discussões, festas e danças próximas a fogueiras gigantescas acesas ao redor do lago Leman, com tambores lembrando ao G8 que os nativos estavam inquietos. Fogueiras deste tipo eram tradição nos protestos de camponeses da região. Houve grandes espetáculos musicais no campo Intergalático e em Genebra, onde ocorreram, também, algumas depredações, à noite, na Opera, no Grande Teatro e num posto de gasolina Elf. A polícia controlou toda a área, principalmente o centro de mídia dos ativistas, o Usina, em Genebra, e houve confrontos com os manifestantes mais radicais do Black Bloc.

No domingo, dia $1^{3}$ de junho, principal dia de ação, foram realizados bloqueios e "abraços" em torno das zonas de exclusão de Lausanne, nas pontes de Genebra, e nas rodovias que levavam dos hotéis de Genebra ao cais de Lausanne, além de grandes demonstrações no trecho de $6 \mathrm{~km}$ entre Annemasse e Genebra, a partir das 10h, com manifestantes partindo tanto da França quanto da Suíça. Cerca de duzentos mil ativistas participaram dos eventos. Com isso, a cúpula teve atrasos de mais de duas horas. Os protestos foram realizados por diferentes tendências, desde o Anthrax, que chegou a usar fogo nos bloqueios, até os blocos de pacifistas, de ciclistas e de "dançarinos". No final do dia, houve detenções, com ações violentas e arbitrárias por parte da polícia, atitudes surpreendentes num país como a Suiça, incluindo prisões em massa e uso pesado de gás lacrimogêneo, de balas de borracha e de bombas de efeito moral. Dois manifestantes ficaram gravemente feridos.

Ainda no domingo, entre as oito e as dez e meia da noite, ocorreu o cerco e a invasão do centro de mídia no Centro Social Usina. Manifestantes foram agredidos, passaportes foram confiscados e realizadas 11 prisões. A produção de informações não chegou a ser interrompida. $O$ motivo alegado para a invasão foi o de que o Centro seria a base para os protestos com características de violência, mas nada neste sentido foi encontrado. Na realidade, todas as atividades no Centro Social foram marcadas pela transparência, incluindo aquelas ligadas ao site de mobilização ao vivo Geneva03. De acordo com o Indymedia, tem sido 
freqüente a tentativa de vincular atividades de mídia independente com a violência. Na mobilização de Gênova contra o G8, em julho de 2001, o Centro de Mídia Independente também havia sido atacado.

$\mathrm{Na}$ segunda-feira, ainda houve bloqueio de pontes em Genebra, reprimidos com violência pela polícia, e na terça se encerraram as manifestações na cidade, com aqueles que permaneceram nos acampamentos em torno do lago Leman, com apoio de militantes locais.

\section{A resistência via hipermídia}

Todos estes movimentos foram sustentados por uma ampla articulação via Internet, com inúmeros sites de apoio, entre os quais se destacaram o do Centro de Mídia Independente - Indymedia, www.indymedia.org, como sempre; o projeto www.geneve03.org, dedicado à divulgação on line de arquivos sonoros e visuais (livestreem); o G8 Summit Evian June 2003 - Report \& Photos, http:/ /www.nadir.org/nadir/initiativ/agp/free/evian/index.htm\#\#lausanne; e o site do Attac, www.attac.info/g8evian, todos voltados para a cobertura dos eventos, com informações, mapas e imagens.

$\mathrm{O}$ www.antig8.info, organizou os links. E outros, como o Contre-attaque, http://squat.net/contre-attaque/english/index $2 . h t m$, e o G8circus http://www.g8circus.org.uk, foram marcados pela combatividade.

Contudo, conforme já adiantamos acima, não nos interessa aqui, simplesmente, a operacionalização de sites e sim pesquisar se as organizações voltadas para o estímulo à participação de âmbito global têm utilizado a hipermídia, como forma de mobilização, em toda a sua efetividade. Nossa hipótese é de que isto ainda não esteja ocorrendo e as observações relativas à Cúpula em Evian também parecem caminhar neste sentido.

Isto porque a principal preocupação dos sites pesquisados, incluindo aqueles que destacamos acima, é a de fornecer informações sobre o evento e as mobilizações de protesto. Em nenhum deles se verificou a intenção de utilizar a plataforma hipermídia para ampliar as manifestações de protesto de forma a transformá-las em eventos 
globalizados em rede, ao vivo. Ao contrário, todos os esforços se concentraram em oferecer as melhores condições possivivis para estimular a presença física nos eventos programados, por meio da reprodução de mapas, da veiculação de informações relativas à organização dos acampámentos, dos meios de transportes, da programação dos protestos e até mesmo de como deveriam se comportar aquelès que estivessem fazeñdo a cỏbertura das manifestações para: veiculação em sites. Sempre há a preocupação, ainda, de fornecer avaliações prévias de conjuntura, incluindo textos teóricos, e também sobre o que ocorreu. Após os eventos, os sites permanecem ná rede por um período variável.

No caso do site do G8circus, existiam informações úteis para os ativistas, cronograma de ações e aconselhamentos legais e de saúde. O predomínio era da linguagem verbal, com poucas cores e fotos. O Contre-attaque e o Attac também apresentaram informações verbais, com ênfase em documentos, além de mapas e ilustrações. Já o G8 Summit Evian se propôs a ser um site completo, com documentos e informações pré-encontro, incluindo notícias da grande mídia, cobertura diária, discussões na fórma de artigos, e até mesmo avaliações sobre o impacto dos "dias de resistência", após seu término. O predomínio era da cor branica com fontes em vermelho e preto, incluindo fotos. No caso do Antig8.info, a idéia era fornecer um filtro de links por lingua, por número de acessos, por tendências ou locais, sem maiores pretensões de caráter visual, limitando-se à linguagem verbal e às cores cinza e branco.

O destaque, como sempre, coube ao Centro de Mídia Independente, o Indymedia (www.indymedia.org). O centro foi criado em Washington, en abril de 2000 , para gerar versões informativas autônomas frente à grande mídia a respeito dos protestos contra a reunião do Banco Mundial e do FMI. Hoje, a organização se estende a vários países, com sites organizados por grupos locais, inclusive em cidades brasileiras.

Num documento prévio, preparatório para o encontro, o centro definia como objetivos principais na área de comunicação:

1. Contribuir para a comunicação interna entre os manifestantes e acampamentos, com atualidade e precisão; 
2. Troca de conteúdos políticos com o público;

3. Documentação dos protestos e distribuição da informação para todo o mundo. Como já se previa um incremento da cobertura ao vivo, pois os mais diversos grupos políticos foram convidados a participar por meio do envio de material sonoro e visual, recomendou-se cautela em função da segurança do movimento frente à repressão policial. Nos últimos eventos, a polícia tem visado os portadores de câmeras, e apreendido o material, que pode vir a ser usado por autoridades judiciais.

Localizado no local chamado Usina, em Genebra, o centro de mídia rẹalizou um trabalho de grande fôlego, a partir de seu site principal que oferecia inúmeros links para sucursais em todo o mundo, abrangendo eventos, notícias, coberturas on line (newswire), análises aprofundadas, listas de contatos e apoios. As informações estavam disponíveis em formato multicódigos, por meio da confluência de informações sonoras (incluindo rádio), visuais (cores, ilustrações, fotos e vídeos) e textuais (envolvendo trabalho com a tipologia). Todas estas atividades foram marcadas, ainda, pelo estímulo à interatividade de qualquer usuário da rede, incluindo a organização do processo, por meio de listas de discussão. No caso de Evian, participaram da cobertura os centros de mídia independente da Suíça, do País Basco, de Paris, Nantes e Barcelona, da Itália, da Holanda, e, especialmente, do Reino Unido.

O Indymedia do Reino Unido divulgou, ao final do encontro, uma avaliação na qual afirmava que a multiplicidade de canais de informação tornou a cobertura do evento a principal experiêtncia do grupo até agora. Foram usados telefones comuns e celulares, mensagens em texto, IRCs, rádios e vídeos pela rede (radiostreams e videostreams), listas de emails, além do suporte de outros sites $\mathrm{e}$ respectivos links. O trabalho no centro de mídia foi descrito com as seguintes palavras:

Foi excitante, mas, às vezes, excessivo, considerando que éramos mais gente do que nunca. A rapidez, a necessidade de fazer dez coisas ao mesmo tempo, a falta de uma estrutura prévia e de prioridades nos empurraram para o limite. 
Não enfrentamos gás lacrimogêneo, mas a exaustão depois de dias na frente do computador, esquecendo completamente necessidades fisicas básicas. Foi como Matrix. Uma pessoa ficou online por 36 horas. Midia direta. A dinâmica de se 'estar lá' se espalhou das ruas para o mundo virtual.

\section{Uso efetivo versus possibilidades da resistência hipermidia}

A última sentença, acima, nos conduz de volta à preocupação principal descrita na introdução. Será que, de fato, a dinâmica de se "estar lá" se espalhou das ruas para o mundo virtual ? Na verdade, a partir da observação dos sites, constatamos que não podemos dizer, sequer, que houve a preocupação de "espalhar" a dinâmica de se "estar lá". Com isso, e de acordo com nossa hipótese, muitas das possibilidades da linguagem multicódigos da hipermídia se perderam, em vista de uma mobilização realmente global.

A linguagem hipermídia, de fato, tem se desenvolvido bastante, nos últimos dez anos, no sentido de ampliar significativamente o compartilhamento de qualidades entre o que se quer representar e os respectivos processos sígnicos, por causa de seu caráter multicódigos. É o caso, por exemplo, do site do Indymedia, que explora, em grande medida, possibilidades sonoras, visuais e interativas, além de realizar um trabalho com o verbal, aproximando-o de seus objetos por meio de formas e cores, entre outros recursos gráficos, e, ainda, ao testar configurações redacionais mais adaptadas ao suporte eletrônico.

É certo que esta linguagem não se constitui ainda como forma de expressão efetivamente revolucionária, em vista das dificuldades de recepção de sons e imagens no padrão da TV digital pelos atuais computadores pessoais, implicando em interatividade limitada. Espera-se que a disseminação da banda larga altere este contexto a curto e médio prazo. Ainda assim, é flagrante a evolução das relações de compartilhamento de qualidades entre signo e objeto comparadas a um período bastante recente no qual o ativismo político ficava 
praticamente limitado a representações verbais, seja na esfera da escrita impressa, ou do verbal falado, isto quando dispunha de rádios não-comerciais, tendo em vista os custos proibitivos de impressão de imagens a cores e, mais ainda, de transmissões de TV. Hoje, a Internet fornece recursos multimídia a custos acessíveis a todos.

Assim, se o problema não se situa mais, tão destacadamente, na esfera do signo, ele mesmo, o quadro é diferente quando lidamos com os processos de apropriação do que se quer representar, ou seja, quando se trata das relações com o objeto. Verifica-se, é certo, que o Indymedia e demais grupos de ativistas realizam um esforço sincero para estabelecer conexões dinâmicas e existenciais com os objetos que visam representar, construindo sites que antecipam e preparam as mobilizações, montando centros de mídia, se arriscando em confrontos com a polícia para obter sons e imagens, divulgando, e, ain$\mathrm{da}$, avaliando, de forma sistemática e em rede, o impacto das ações realizadas, incluindo as de mídia.

Contudo, tal concentração de esforços para a representação das ações apenas no local onde se realiza o evento a ser denunciado e combatido não nos parece a atitude mais adequada para o que seria, de fato, uma mobilização global. Ainda predomina, nesses casos, uma concepção de uso da linguagem voltada para particularidades, característica do recente período hegemônico do pós-estruturalismo, conforme defendemos em outros trabalhos (Pimenta, 1999B e $2001 \mathrm{~B}$ ). Vale reproduzir, aqui, um dos parágrafos finais de um destes artigos, que explicita melhor este ponto:

Esta nova base técnica permite a superação dos meios tradicionais de expressão signica que, por sua própria constituição lógica, conduzem a produtos, incluindo os de massa, que reproduzem processos mentais meramente classificatórios e hierarquizantes, estimulando particularidades grupais e individualistas. Esta tendência se disseminou ainda mais com o sucesso teórico do estruturalismo e do pós-estruturalismo, que impôs o modelo lingüistico como paradigma de análise e de produção signica, e, até mesmo, como pretenso instrumento revolucionário, 
por meio de Foucault é Derrida, entre outros. Na verdade, a defesa de particularidades é incompativel com o respeito a valores universais. Nesse sentido, a radicalização de posturas grupais e individualistas tem levado muitas vezes a movimentos dé caráter neofascista, inclusive de tendências ditas de esquerda. (Pimenta, 1999B, p.11)

É claro que os sites de ativismo global estão longe deste limite, porém lhes falta, numa certa medida, consciência de uso de linguagem que traduza valores universais e, de fato, se apóie neles, incluindo aí concepções teóricas. É o caso desta restrição do âmbito do objeto, que faz com que as representações sígniças, tais como às realizadas em Evian, não atinjam seus objetivos'de forma plena, ou seja, não são criadas condições para a alteração de hábitos mentais e de conduta de seu público alvo, ou seja, a ampla maioria que se encontra submetida à apatia e ao conformismo gerados pela atual cultura globalizada: A estratégia de conicentrar os esforços alternativos de mídia no local dos eventos parece, ainda, querer aproveitar a cobertura de imprensa oficial, o que acaba por reforçar este tipo de representação dos fenômenos, contrariando todo o movimento de denúncia da espetacularizaçã̃o iniciado pela Escola de Frankfurt e pelo Situacionismo (Vaneigem, 2002).

A alternativa seria, então, ampliar a noção de objeto, de modo a explorar, em toda a sua capacidade, os recursos multicódigos que a hipermídia coloca ao alcance de todos, no sentido da mudança de hábitos e da mobilização pólítica global. Isto pode se dar, fundamentalmente, pelo abandono da focalização exclusiva no evento a ser denunciado, "èm troca de representações sígnicas de mobilizações co-ocorrentes em diversas partes do planeta. Tal atitude serviria, ainda, como estímulo à descentralização das ações, o que poderia gerar a consequência altamente positiva de transformar o caráter meramente reativo das mobilizações, tal como a que ocorreu em Evian, em unia ação global contínua, autônoma e singular, propositiva em si mèsma. 
Os sites poderiam utilizar, assim, os recursos multicódigos da hipermídia para recuperar qualidades da mobilização de forma ampla, com sons, imagens, interatividade e textos, mas, agora, com a determinação de gerar signos com relaçôes existenciais com o objeto "ativismo global". Conforme já apresentei em outros trabalhos (Pimenta, 2002 e 2003), a mudança de hábitos mentais e de condutas está relacionada à construção de signos genuínos, e para isso, é fundamental seu aporte sobre relações existenciais com o objeto igualmente genuínas. Reproduzo, aqui, um parágrafo de um destes dois trabalhos:

Mais do que isto, a degenerescência estimula a mudança de hábitos mentais, seja quando o processo sígnico é marcado pela dinâmica das trocas existenciais da esfera dos objetos, ou seja, por uma degenerescência de primeiro grau, ou quando compartilha qualidades com estes mesmos objetos, ou seja, sofre uma degenerescência de segundo grau. Neste caso, estamos frente a um importante fator de geratividade, pois, segundo Peirce, a constante multiplicaçäo de signos, a partir do estágio simbólico, ou seja, quando estão aptos a representar algo para uma ampla gama de mentes interpretadoras, deve-se particularmente aos icones: "Simbolos crescem. Eles ganham existência a partir do desenvolvimento de outros signos, particularmente de ícones, ou de signos mistos que compartilham as qualidades dos icones e dos símbolos. (Peitce, 1931-1958; 2.302) [Pimenta, 2003, p.03]

Daí, ao valorizarem as relações de qualidade com o ativismo, mas também as existenciais, em sua amplitude global, e não apenas com eventos localizados numa determinada área geográfica, estes sites estariam mais aptos a gerar signos genuinos e, daí, servirem de suporte para transformações de hábitos mentais e de conduta no sentido desejado pelos ativistas, ou seja, da construção da democracia participativa e de um internacionalismo renovado. 


\section{Bibliografia}

AGUITON, C. 2002. O Mundo nos Pertence. SP: Viramindo.

BEY, H. 2001.TAZ -Zona Autônoma Temporária. SP: Conrad.

BORON, A. 2002. Império e Imperialismo. Buenos Aires: CLACSO.

COCCO, G. e HOPSTEIN, G. 2002. As Multidões e o Império. Rio: DP\& ${ }^{a}$

COTTON, Bob e OLIVER, R. 1997. Understanding Hypermedia 2.000 London. Phaidon.

GUARNACCIA, M. 2001. Provos: Amsterdam e o nascimento da contracultura. SP: Conrad.

HARDT, M. \& NEGRI, A: 2001. Império_ RJ: Record.

LUDD, N. 2002. Urgência nas Ruas: Black Block, Reclaim the Streets e os dias de ação global. SP: Conrad.

PEIRCE, C. S. 1931-1958. Collected Papers. 8 vols. Cambridge: Harvard Univ. Press.

PIMENTA, F. J. P. 1993. "Tecnologia Eletrônica e Jornalismo" in São Paulo em Perspectiva. Vol 7 no. 4. pp 75-80. SP. Fundação SEADE.

1998. "Duas Tendências em Semiótica" in Lumina. V.1/1. pp. 85-110. JF: EdUFJF.

. 1999A. "Intersemiose e Multimídia" in Ícone. V.1/4. pp. 6370. Recife: Universitária.

. 1999B. "Novo Conservadorismo e Ambiente Hipermídia" in Fronteiras - estudos midiáticos. Vol 1. no. 1. São Leopoldo: Ed. da UNISINOS.

1999C: "Webdesign e Informação" in Lumina. Vol 2. no. 2. pp.67-78. JF: EdUFJF.

2001A. "Desafios para a Esquerda no Ciberespaço" in Anais do V Congresso de Ciências, Humanas, Letras e Artes das IFES/ MG. Ouro Preto: Ed. da UFOP.

2001B. "Pensar Globalmente e Agir Localmente: contribuições da Semiótica de Peirce" in Anais do V Cong. Bras. de Semiótica: SP: Ed. Fac. Belas Artes. 
2002. "Produções Multicódigos e o Conceito de Signo Genuíno em Peirce" in Anais do XXV Congresso da INTERCOM. Salvador: Ed. da UFBA.

2003. "Hipermidia, Ativismo e Novos Hábitos" in Anais do I Enrecom. JF: EdFACOM/UFJF.

SEOANE, J. \& TADDEI, E. 2001. Resistências Mundiais. Petrópolis: Vozes.

TODD, E. 2003. Depois do Império. Rio: Record.

VANEIGEM, R. 2002. A Arte de Viver para as Novas Gerações. SP: Conrad.

WAINWRIGHT, H. 1998. Uma Resposta ao Neoliberalismo. Rio: Jorge Zahar Ed. 